\title{
A Journey of Process Safety Management Program for Process Industry
}

\author{
${ }^{1}$ Hanida Abdul Aziz and ${ }^{2}$ Azmi Mohd Shariff

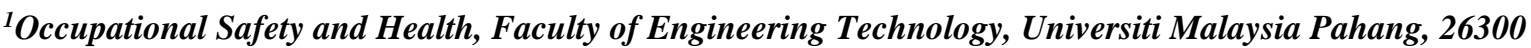 \\ Kuantan, Pahang, Malaysia \\ ${ }^{2}$ Centre of Advanced Process Safety, Department of Chemical Engineering, Universiti Teknologi \\ PETRONAS, 32610 Seri Iskandar, Perak \\ ${ }^{1}$ hanidaaziz@ump.edu.my
}

\begin{abstract}
The growth of process industries and global economies are dependent on technology advances and innovations. However, the effects of these advancements often lead to more complex processes and comparatively severe operating conditions such as high pressure, temperature and reactive chemical with exotic chemistry. With the rapidly increasing scale and complexity of the process, it is becoming harder to control accidents in process plants. In most of the past situations, it appears that accidents could not be controlled solely by engineering practices and traditional occupational safety but should be immersed with safety management programs specifically Process Safety Management (PSM) to enhance the effectiveness of technical solutions. This paper addressed PSM program as stipulated by OSHA 29 CFR 1910.119. The PSM standard was implemented following a number of disasters, including accidents in Bhopal, India (1984) and Pasadena, Texas (1989). In Malaysia, Control of Industrial Major Accident Hazards (CIMAH) 1996 Regulation which has the requirements attribute to PSM standard also discussed.
\end{abstract}

Index Terms- Process Safety Management, Risk Management Program, Process safety, Safety management system, Process Industry

\section{INTRODUCTION}

Safety management programs are recognized and accepted worldwide as best-practice methods for managing risk. This need is based on the understanding that once a risk is accepted, it does not go away; it is there waiting to happen unless the management system actively monitors the company operations for concerns and taking proactive actions to correct potential problems [1-2]. Having an effective management system for process-related hazards (fire, explosion, release of toxic materials, etc.) is therefore a critical corporate objective in the process industries. An approach widely used in the process industries is Process Safety Management (PSM) program.

PSM is the application of management principles to identify, understand and control hazards while preventing process-related injuries and accidents. PSM focused on prevention of, preparedness for, mitigation of, response to, and restoration from catastrophic release of chemicals or energy [3]. PSM entails development and implementation of program or system to ensure that the practices and equipment used in hazardous processes are adequate and maintained appropriately. It requires on-going effort to prevent catastrophic accidents involving hazardous process materials and energy. The PSM implementation provided better impacts on safety of process industries such as fatality, injury and near miss were decreased, quality and productivity were improved, technical data were well reorganized, the number of emergency shutdown cases was decreased, the property damage was reduced, and the problem of reinsurance was solved [4]. 


\section{PROCESS SAFETY MANAGEMENT OF OSHA}

The US Occupational Safety and Health Administration (OSHA), which was created in 1970, began its first major efforts in chemical process safety in the early 1980s following several catastrophic events, as shown in Figure 1. This timeline illustrates process safety history in relation to major OSHA process safety milestones. A release of Methyl Iso-Cyanate (MIC) at Bhopal (1984) and methylchloride at WV facility have prompted OSHA to inspect all US facilities that produced MIC. The inspection Union Carbide led OSHA to believe that it needed to look beyond its then current standards and look at management systems, work practices, and protective systems [5-6].

Soon after the MIC and Union Carbide Inspections were completed, OSHA began a special emphasis program aimed at chemical manufacturers. The purpose of this Chemical Special Emphasis Program (Chemical SEP) was to determine industry practices for the prevention and mitigation of catastrophic chemical releases, and to determine how OSHA could protect chemical industry workers within its legal authorities, resources, and policies. The Chemical SEP lasted from January 1986 until September 1986, and targeted manufacturers of high hazard substances. During the inspections, Compliance Officers reviewed programs rather than focusing only on physical conditions. OSHA realized that many of its standards at the time may not cover the numerous hazards found in chemical plants, and encouraged Compliance Officers to look for industry standards that applied to those hazardous conditions [5].

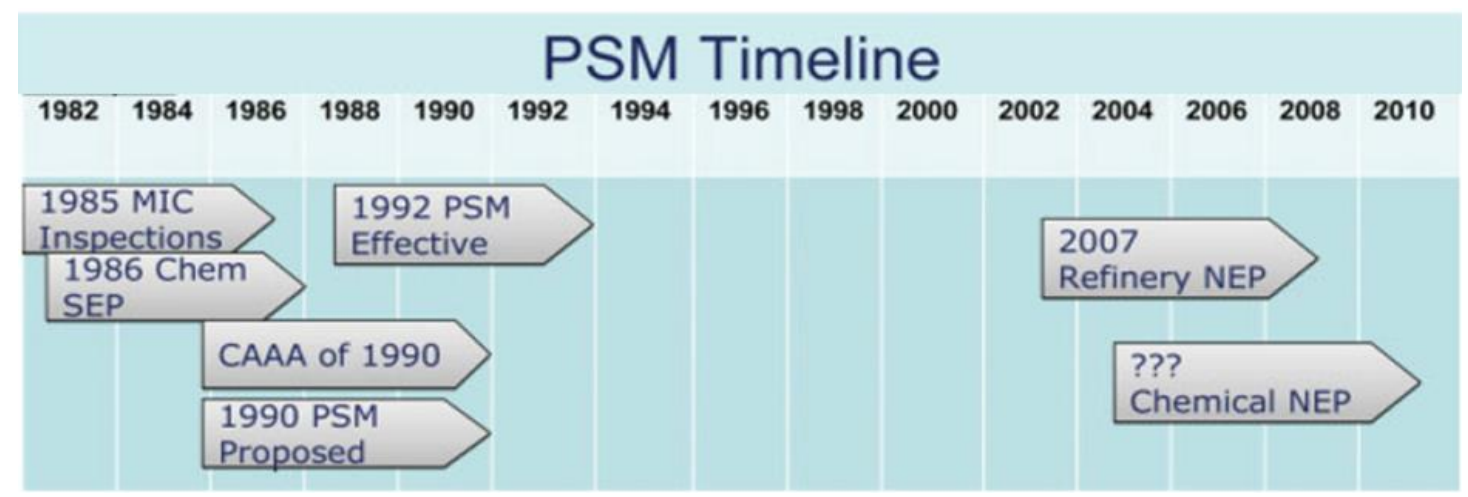

Figure 1: OSHA PSM Timeline [5]

Following the Chemical SEP, several more catastrophic accidents occurred. On July 17, 1990, OSHA through Federal Register (55 FR 29150) documentation, proposed a standard entitled "Process Safety Management of Highly Hazardous Chemicals". This standard list the requirements for the management of hazards associated with processes using highly hazardous chemicals. This is to encourage a safe and to help assure safe and healthful workplaces. The notice of proposed rulemaking invited comments on any aspect of the proposed standard. OSHA received more than 175 comments in response to the notice of proposed rulemaking. In addition to these comments, the hearings resulted in almost 4,000 pages of testimony and almost 60 post-hearing comments and briefs. In November 1990, Congress passed the Clean Air Amendments of 1990 mandating that OSHA promulgate a rule on chemical process safety. In February, 1992 PSM is regulated through the PSM standard, 29 CFR 1910.119, titled Process Safety Management of Highly Hazardous Chemicals [5-7].

The standard mainly applies to manufacturing industries particularly, those pertaining to chemicals, transportation equipment, and fabricated metal products. It also applies to pyrotechnics and explosives manufacturers covered under other OSHA rules and has special provisions for contractors working in covered facilities. In each industry, PSM applies to those companies that deal with any of more than 130 specific toxic and reactive chemicals in listed quantities (Appendix B of PSM 29 CFR 1910.119), it also includes flammable liquids and gases in quantities of 10,000 pounds $(4,535.9 \mathrm{Kg})$ or more [7]. 
PSM of OSHA comprises of 14 elements that are used to manage facilities, technology, and personnel as summarized in Table 1 Prior to the implementation of the PSM standard, OSHA predicted the impact of this rule. OSHA also anticipated about 24,939 establishments that could be covered, including 127 industry subgroups and three million employees including contractors. The standard was expected to prevent 132 deaths and 767 serious illnesses and injuries in the first five years, and twice that by the second five years [5-6]. It is also believed that, the OSHA PSM regulation has excellent requirements that could and should prevent casualties if plants follow the regulation as intended [8-9].

Table 1: Overview of OSHA PSM Element [7]

\begin{tabular}{|c|c|}
\hline PSM ELEMENT & DESCRIPTION \\
\hline $\begin{array}{c}\text { Employee } \\
\text { Participation }\end{array}$ & $\begin{array}{l}\text { Ensure that workers and their representatives are consulted and have access to } \\
\text { information regarding all PSM elements. }\end{array}$ \\
\hline $\begin{array}{l}\text { Process Safety } \\
\text { Information }\end{array}$ & $\begin{array}{l}\text { Maintain complete and accurate information on the process technology, process } \\
\text { equipment, and hazardous characteristics and physical properties of all chemicals } \\
\text { and intermediates for all covered processes. }\end{array}$ \\
\hline $\begin{array}{l}\text { Process Hazard } \\
\text { Analysis }\end{array}$ & $\begin{array}{l}\text { Identify and assess process hazards for each covered process, and take action to } \\
\text { manage risk. }\end{array}$ \\
\hline Operating Procedures & $\begin{array}{l}\text { Provide clear written instructions for safely conducting activities at each covered } \\
\text { process that address operating limits, safety and health considerations, and safety } \\
\text { systems and their functions. }\end{array}$ \\
\hline Training & $\begin{array}{l}\text { Provide initial and refresher training with a means of verifying employee } \\
\text { understanding for all employees involved in operating a covered process. }\end{array}$ \\
\hline Contractor & $\begin{array}{l}\text { Ensure that subcontractor operations do not compromise the level of safety on or in } \\
\text { the vicinity of a process using Highly Hazardous Chemicals (HHCs). }\end{array}$ \\
\hline $\begin{array}{c}\text { Pre-Startup Safety } \\
\text { Review }\end{array}$ & $\begin{array}{l}\text { Perform safety reviews for new and modified facilities prior to operation when the } \\
\text { modification is significant enough to require a change in the process safety } \\
\text { information }\end{array}$ \\
\hline Mechanical Integrity & $\begin{array}{l}\text { Ensure the integrity and safe operation of process equipment through inspection, } \\
\text { testing, preventive maintenance, and quality assurance. }\end{array}$ \\
\hline Hot Work Permit & $\begin{array}{l}\text { Ensure that appropriate measure is take in any time non routine works, specifically } \\
\text { hot work such as welding operations are performed on or near covered process areas } \\
\text { that might introduce the potential for increased risks of fires and explosion. }\end{array}$ \\
\hline $\begin{array}{c}\text { Management of } \\
\text { Change }\end{array}$ & $\begin{array}{l}\text { Establish and implement written procedures to manage changes (except for } \\
\text { replacements in kind) to process chemicals, technology, equipment, and procedures, } \\
\text { and to facilities that affect a covered process }\end{array}$ \\
\hline Incident Investigation & $\begin{array}{l}\text { Using a written procedure, provide a team investigation of any incident which results } \\
\text { in, or could reasonably result in, a catastrophic release of a highly hazardous chemical. } \\
\text { Each investigation must be documented in a written report and findings and } \\
\text { recommendations resolved in a timely manner. }\end{array}$ \\
\hline $\begin{array}{l}\text { Emergency Planning } \\
\text { and Response }\end{array}$ & $\begin{array}{l}\text { Establish and implement an emergency action plan for the entire plant that is in } \\
\text { compliance with } 29 \text { CFR 1910.38(a) and that also addresses small releases }\end{array}$ \\
\hline Compliance Audits & $\begin{array}{l}\text { Ensure that the PSM program is operating in an integrated and effective manner in } \\
\text { compliance with PSM requirements. }\end{array}$ \\
\hline Trade Secret & $\begin{array}{l}\text { Ensure all information is available to support the PSM Rule. When necessary, } \\
\text { confidentiality or nondisclosure agreements may be used. }\end{array}$ \\
\hline
\end{tabular}

Full implementation of the PSM work process should also include a systematic approach in managing the PSM process and activities. The process requires that the program can ensure continuity when personnel change, and to include quality assurance such as steps to plan, implement, check, and correct the PSM implementation program. Work process failures should be addressed by improvement of documentation already in place, promptly resolving PSM-related recommendations of all types, and 
keeping track of the ever-changing Recognized And Generally Accepted Good Engineering Practices (RAGAGEP) that applies to many aspects of the PSM program. In addition, it is essential to get management support/involvement and to establish follow-up systems to ensure all work activities are complete and adequately documented. Instituting complete work processes will improve the PSM program, its efficiency, and help reduce the chance of citations [4].

\section{III. $\quad$ RISK MANAGEMENT PROGRAM 40 CFR 68}

The other accident prevention program contained in the amended Clean Air Act (CAA) (1990) called for EPA to develop regulations to prevent and respond to chemical accidents that could affect the public and environment off-site. EPA met this obligation in 1996 by promulgating the Risk Management Program (RMP) regulations (40 CFR 68) [10]. EPA is extending PSM requirements with the proposed RMP. The RMP focuses on reducing chemical incident risk at the local level, to aid emergency responders in developing strategic preparedness and response plan and to educate the general public about chemical hazards. The RMP is similar to OSHA's PSM standard, as it covers many of the same toxic and flammable substances, and requires virtually the same set of accident prevention requirements as the OSHA standard. However, while the accident prevention elements of PSM and RMP are nearly identical, EPA Risk Management Program contains several additional requirements beyond those contained in OSHA PSM. These include the following:

a) Facilities must prepare a history of accidental releases occurring over the past five years.

b) Facilities must perform an Offsite Consequence Analysis (OCA), which is an analytical estimate of the potential consequences of hypothetical worst case and alternative accidental release on the public and environment around the facility.

c) Facilities must submit a summary report, called a Risk Management Plan to the EPA. The plan contains the facility's five-year accident history, a summary of its accidental release prevention program, its offsite consequence analysis, and a summary of its emergency response plan.

d) EPA must make all Risk Management Plans available to state and local governments and the Public.

\section{RISK-BASED PROCESS SAFETY}

The American Institute of Chemical Engineer (AIChE) created the Center for Process Safety (CCPS) in 1985 to develop and disseminate technical information to be used in the prevention of major chemical accidents. CCPS has created Risk-based Process Safety (RBPS) and name it as framework for the next generation of Process Safety Management (PSM). Figure 2 tabulates the elements of RBPS that have been built on a foundation of four pillars including commitment to process safety, understand hazards and risk, manage risk and learn from experience [11]. These pillars are further divided into 20 elements. The 20 RBPS elements build and expand upon the original 12 elements proposed in the 1989 work. The RBPS elements were meant to be evaluated by companies, which may then decide to implement some aspects of these elements, based on thoughtful consideration of their existing PSM systems. Companyspecific and local requirements may result in very different RBPS activities based on the perceived needs, resource requirements, and existing safety culture of facility. 
INTERNATIONAL JOURNAL OF ENGINEERING TECHNOLOGY AND SCIENCES (IJETS) Vol.8 (1) Dec 2017 DOI: http://dx.doi.org/10.15282/ijets.8.2017.1.10.1085

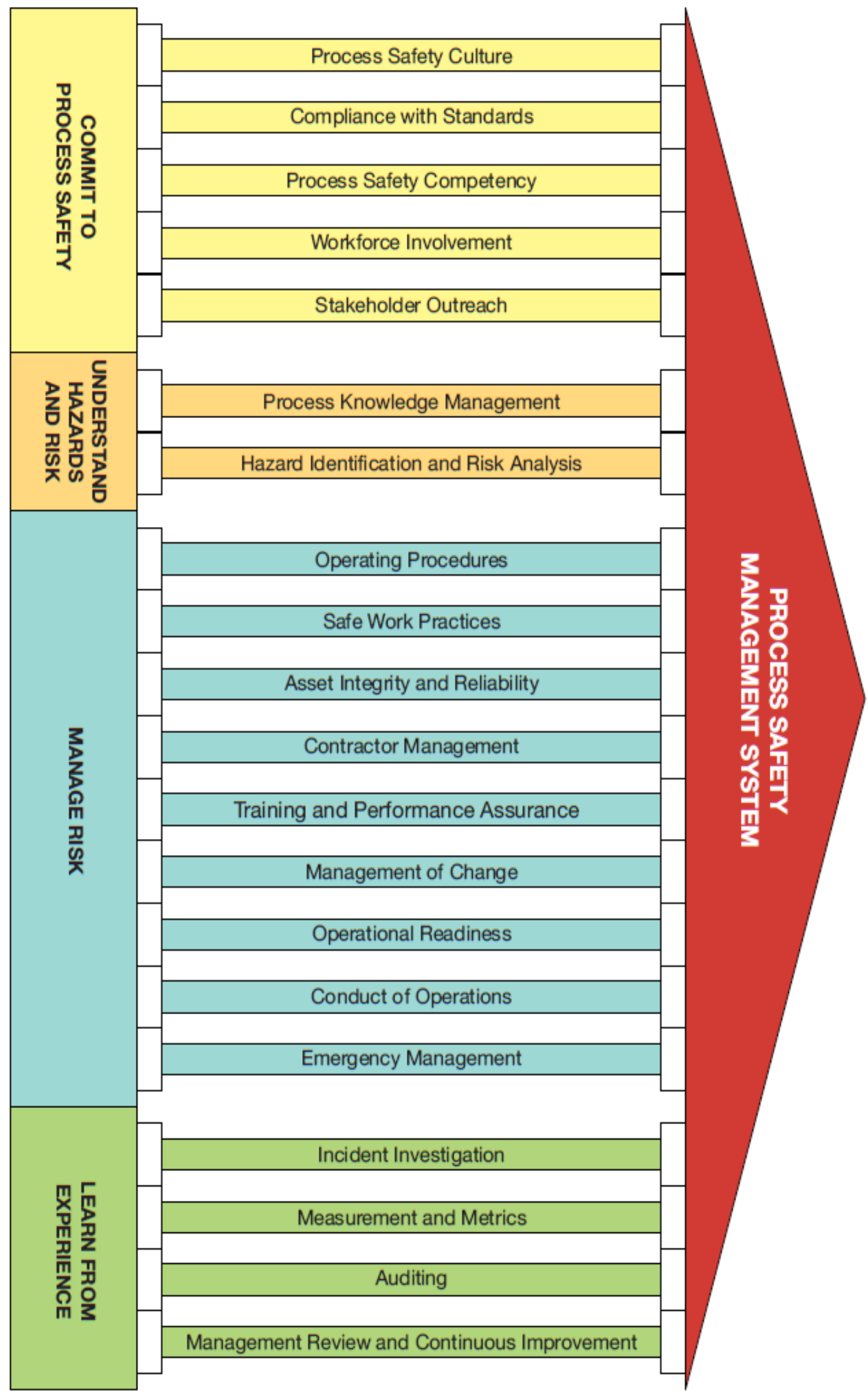

Figure 2: Risk Based Process Safety Elements [11] 


\section{CONTROL OF INDUSTRIAL MAJOR HAZARDS (CIMAH) 1996}

Occupational Safety and Health Regulations (Control of Industrial Major Accident Hazards) or CIMAH is enacted in 1996 in Malaysia by the Department of Occupational Safety and Health (DOSH). This regulation is based on CIMAH United Kingdom (UK 1984) in order to prevent the possibility of any major accidents in industries. This is due to the series of major accidents happened worldwide such as toxic release in Bhopal (1984), Flixborough disaster (1974) and locally in Malaysia such as fire and explosion at Bright and Sparkles (1991) [12]. Table 2 tabulates the coverage of the safety management elements in CIMAH 1996 with regard to PSM. There were 12 PSM elements covered under the regulation including EP, PSI, PHA, TNG, MOC, ERP, II, and CA elements.

CIMAH applies to industries that can be classified based on the amount of hazardous materials used, stored or produced. Major Hazard Installation is for the industry handles hazardous material exceeding the threshold value while the Non-Major Hazard Installation is for the industry handles hazardous material exceeds $10 \%$ threshold value. Examples of the threshold value as stated in CIMAH 1996 are chlorine (10 tonnes), ammonia (100 tonnes), hydrogen sulphide (50 tonnes) and hydrogen gas (10 tonnes). The CIMAH Regulations 1996 requires the employer to notify of major hazard installation, prepare emergency plan and notify major accident that occur in their premises. The Industrial Major Hazard Unit formed within DOSH addresses this issue [12].

To ensure the objectives of CIMAH Regulations 1996 implemented effectively, minimum rules are imposed to assist industry to be self-regulated. The implementation of CIMAH is demonstrated through the submission of reports to the regulatory bodies covering hazardous substances which involved in the industrial activities, information related to the installation, systems of management for controlling the industrial activities and risk assessment.

Table 2: The Scope of Safety Management elements in PSM and CIMAH (1996)

\begin{tabular}{ll}
\hline \multicolumn{1}{c}{ PSM } & \multicolumn{1}{c}{ CIMAH (1996) } \\
\hline Employee Participation & Obligations of Manufacturer and Employee \\
Process Safety Information & $\begin{array}{l}\text { Particulars of Installation focusing on process chemical } \\
\text { information (Schedule 5) }\end{array}$ \\
Process Hazard Analysis & $\begin{array}{l}\text { Report on Industrial Activity consulted by Competent } \\
\text { Person (Schedule 6) }\end{array}$ \\
Operating Procedures & - \\
Mechanical Integrity & - \\
Contractor & - \\
Hot Work Permit & - \\
Training & Training for person working on the site (Schedule 6) \\
Management of Change & Modification report (Schedule 6) \\
Pre-Startup Safety Review & - \\
Emergency Planning and Response & On-site and Off-site Emergency Plan \\
Incident Investigation & Major accident notification (Schedule 3) \\
Compliance Audits & Audit and Penalty \\
Trade Secret & -
\end{tabular}




\section{PSM IN CANADA}

The PSM approach is also widely used in the Canadian chemical industries. The PSM elements in this country are tabulated in Table 3, taken from the Process Safety Management Guide of the Canadian Society for Chemical Engineering [13]. The material in the CSChE PSM guide is based on that developed by the CCPS of AIChE [14]. Nevertheless, PSM practice in the Canada does not have the full legislative and regulatory requirements like US or European countries. The Canadian approach has been typically relying more on voluntary initiatives programs [1].

Table 3: Elements of PSM in Canada [13]

\begin{tabular}{ll}
\hline & \multicolumn{1}{c}{ PSM ELEMENT } \\
\hline - Accountability: objectives and goals \\
- Process knowledge and documentation \\
- Capital project review and design procedures \\
- Macess risk management \\
- Process and equipment integrity \\
- Human factors \\
- Training and performance \\
- Incident investigation \\
- Audits and corrective actions \\
\hline
\end{tabular}

\section{PSM IN KOREA}

In March 1995, KOSHA established the Center for Chemical Plants Safety consisting of professional engineers to implement PSM system for the prevention of major industrial accidents. As a result of PSM implementation for 19 years, various kinds of effectiveness were made [16]. The number of major industrial accident including the number of fatalities has been decreased after PSM implementation and productivity has been increased as well as product quality as shown below:

(1) Fatality, injury and near miss were decreased.

(2) Quality and productivity were improved.

(3) Technical data were well reorganized P \&ID, HAZOP and operating procedure.

(4) The number of emergency shut down cases was decreased

(5) The property damage was reduced.

(6) The problem of reinsurance was solved.

\section{CONTROL OF MAJOR ACCIDENT HAZARDS (COMAH)}

The Control of Major Accident Hazards Regulation 1999 (COMAH) implemented the Seveso II Directive (96/82/EC) in Great Britain. They replace the Control of Industrial Major Accident Hazards Regulations 1984 (CIMAH). The regulations were enforced on 1st April, 1999. These regulations were designed to help prevent major accidents involving dangerous substances while minimizing the consequences onto the public and the environment. The regulations were subsequently amended by the COMAH (Amendment) Regulations in 2005 to reflect the changes to Seveso II Directive with the requirement to provide additional information and to demonstrate that they have taken the necessary 
measures to prevent accidents and mitigate the consequences remained [17]. Around 950 sites in Great Britain fall under the COMAH regime (12\% of all Seveso sites in the EU) [18].

COMAH applies to establishments where specified quantities of dangerous substances were present, or likely to be present. The COMAH Regulation includes lists of specified quantities of dangerous substances used to determine whether an establishment is at top or lower tier. Top Tier sites cover larger volumes, presenting more significant hazards and being subject to the highest level of regulatory requirements. The main features of the regulatory and compliance regime are safety report, major accident prevention policy (MAPP), on-site emergency planning, off-site emergency planning, scheduled inspections, investigations and enforcement [17-18].

\section{CONCLUSION}

Application of Process Safety Management (PSM) program in the process industry is very attractive proposition and is expected to bring benefits from safety and overall lifecycle cost perspectives. In 1992, PSM OSHA has been established with 14 elements that are used to manage facilities, technology and personnel. Until today, 20 RBPS elements built and expand by CCPS in order to disseminate vital information to be used in the prevention of major accidents in process industries. Other programs including RMP, COMAH and CIMAH 1996 also have excellent requirements that could and should prevent casualties if plants follow the requirements as intended.

\section{Nomenclature:}

PSM Process Safety Management

CIMAH Control of Installation Major Accident Hazard

OSHA Occupational Safety and Health Administration

RBPS Risk Based Process Safety

RMP Risk Management Program

\section{REFERENCES}

[1] Paul R. Amyotte, Attiq U. Goraya, Dennis C. Hendershot, Faisal I. Khan., "Incorporation of inherent safety principles in process safety management," Process Safety Progress, 26; 333-346. 2007.

[2] Abu Bakar D, Ismail N., "Integral Safety Needs Analysis towards Optimizing Safety Performance in Malaysian-Based Multinational Pipe-Coating Industry", International Journal of Engineering Technology and Sciences, 4; 69-80. 2015

[3] CCPS, Plant Guidelines for Technical Management of Chemical Process Safety New York: CCPS/AIChE, 1995.

[4] Mohd Shariff A, Abdul Aziz H, Abdul Majid N., "Way Forward in Process Safety Management (PSM) for Effective Implementation in Process Industries", Current Opinion in Chemical Engineering Journal , 14; 56-60. 2016.

[5] L. A. Long, "History of process safety at OSHA", Process Safety Progress, 28; 128-130. 2009.

[6] W. G. Bridges, "The cost and benefits of process safety management: Industry survey results", Process Safety Progress, 13; 23-29. 1994.

[7] US Occupational, Safety and Health Administration (OSHA), 1992. Process Safety Management of Highly Hazardous Chemicals (29 CFR 1910.119). Retrieved from http://www.osha.gov.my; 24 Jan, 2017

[8] Josep F. Louvar, "Improving the effectiveness of process safety management in small companies", Process Safety Progress, 27; 280-283. 2008. 
[9] M. Imran Rashid ,Naveed Razman, Tanveer Iqbal, Saima Yasin, Sana Yousaf, "Implementation Issues of PSM in a Fertilizer Plant: An Operations Engineer's Point of View", Process Safety Progress, 32; 59-65. 2013.

[10] EPA. (2010, February 9). Risk Management Plan (RMP) Rule. Available: Available from: http://www.epa.gov/oem/content/rmp/.

[11] A. L. Sepeda. "Understanding Process Safety Management" CEP Magazine, 26-33.2015

[12] K. G. Rampal and J. Mohd Nizam, "Developing regulations for occupational exposures to health hazards in Malaysia", Regulatory Toxicology and Pharmacology, 46; 131-135. 2006.

[13] CSChE, "Process Safety Management," Canadian Society for Chemical Engineering, Ottawa2002. [14] CCPS, Guidelines for Technical Management of Chemical Process Safety. New York: CCPS/AIChE, 1989.

[15] H. M. Kwon, C. J. Lee, D. Seo, II Moon. "Korean Experience of Process Safety Management (PSM) Regulation for Chemical Industry. Journal of Loss Prevention in the Process Industries, 42:2-5. 2016

[16] HSE, "RR703 - Societal Risk: Initial Briefing to Societal RiskTechnical Advisory Group", 2009. [17] DBIS. (2013, March 25). Review of Enforcement in the Chemicals Industry (COMAH). Available: http://www.gov.uk/bis 